\title{
A Structural Utility Mediation Model: China during the Global Financial Crisis
}

\author{
Jan Cham Voon \\ The Open University Malaysia \\ Tel: 60-8-522-616-7175 E-mail: cemsvoon@gmail.com
}

Jan P. Voon

Assoc Prof of Economics at the Department of Economics, Lingnan U

\author{
Received: July 5, 2011 \\ Accepted: July 22, 2011 \\ Published: November 1, 2011 \\ doi:10.5539/ijef.v3n6p141 \\ URL: http://dx.doi.org/10.5539/ ijef.v3n6p141
}

This research was supported by a research grant from Lingnan University (Grant Number DR09D4) and public policy grant awarded by the Research Grant Committee, Hong Kong Special Administrative Region (Grant Number LU3002-PPR-5).

\begin{abstract}
In this paper, we analyze the effects of the 2008 global financial crisis (GFC) on consumer utility in China. Changes in consumer utility wrought by the GFC were measured by changes in consumption and income. Our empirical analysis using structural equation modeling (SEM) showed that the GFC had affected consumer utility directly and indirectly. The indirect effects were mediated by (a) the emotion or anticipatory feeling evoked by the GFC and (b) the change in saving culture or value of the Chinese. We found that route (a), but not (b), was extremely important in mediating the change in consumer utility. Contrary to conventional wisdom, the indirect effect was found to be stronger than the direct effect, pointing to the importance of the role of anticipatory feeling for assessing consumer utility. The model we obtain has a non-significant $p$ value of $0.345(\mathrm{df}=9$; Chi-square=10.063).
\end{abstract}

Keywords: Financial Crisis, Emotion, Saving Culture, Consumer Utility, Mediation, China

\section{Introduction}

Consumer utility (CU), measured by consumptions of goods and services, has widely been used for assessing the welfare of consumers. In the past, however, psychological influences were often excluded from the assessments of CU (Varian, 2010). Yet psychological states generated under conditions of uncertainty are important in real life and, hence, omission of which could give rise to inaccurate or erroneous assessment of CU. In a recent paper, Caplin and Leahy (2001) showed that anticipatory feelings such as anxiety and fear emanating from uncertainty were important in contributing to utility assessment. They assume that $\mathrm{CU}$ is a function of consumption and emotion. Contrary to Caplin and Leahy (2001), this paper hypothesizes emotion to be a mediating causal factor rather than a measure of utility. This hypothesis is empirical tested in this paper.

The 2008 global financial crisis (GFC) has the impacts of increasing unemployment or threatening job insecurity as employers' bottom lines are adversely affected. In this paper, we examine if the utility of Chinese consumers was affected by the GFC. China is of empirical interest: for example, it has the largest consumer market; job insecurity is a real issue since many workers are deprived of proper social safety nets and formal job contracts; and China has relatively high saving rates. Coupled with its exchange rate control and strong economic growth, some economists think that China might not be significantly affected by the GFC. We also examine whether the indirect mediating effects are significantly larger (or smaller) than the direct effects. If the mediating effects are important, then previous studies measuring only the direct effects could lead to underestimations of consumer welfare.

Using structural equation modeling (SEM) (see Kline, 2010; Byrne, 2010; Yang \& Green, 2010; Bollen \& Davis 2010) (note 1), we are able to illustrate and examine the validity of our structural utility mediations model in which changes in utility of Chinese consumers due to the GFC were indirectly mediated or facilitated by anticipatory feelings and saving cultures (paths a, b, d, e and f) as well as directly affected (path c in Figure 1). Our empirical analysis in this paper shows that the GFC has significantly affected the Chinese consumers despite its relatively high 
growth advantage. The indirect impact of the GFC on consumer utility as mediated by anticipatory feelings (paths a and b) was reported to be larger than its direct effect. We also found that the high saving culture/value of the Chinese served as an important albeit a weaker mediator between CU and the GFC.

\section{Theory of Utility Mediation}

\subsection{Measures of Consumer Utility}

Utility measures a person's well-being. The relevant concept is ordinal utility, which emphasizes ordering but not magnitude of preferences. Consumer utility is often expressed as a function of consumptions:

$$
\mathrm{U}=\mathrm{f}\left(\mathrm{X}_{1}, \mathrm{X}_{2}, \ldots . \mathrm{X}_{\mathrm{n}}\right)
$$

where $X_{1}$ is consumption of good, $X_{2}$ is consumption of good 2, etc, and $n$ denotes the total number of goods and services. In microeconomic theory, consumption is expressed as a function of income and prices:

$$
X_{i}=f\left(P_{i}, P_{j}, Y_{c}\right) \text {. }
$$

where $P_{i}$ is price of good $i, P_{j}$ is price of good $j$ (which may be seen as a composite good on a two dimensional diagram) and $Y_{c}$ is current income of the consumer. We also posit that:

$$
\mathrm{Y}_{\mathrm{c}}=\Sigma\left(\mathrm{P}_{\mathrm{i}} \mathrm{X}_{\mathrm{i}}+\mathrm{P}_{\mathrm{j}} \mathrm{X}_{\mathrm{j}}\right)
$$

Equation (3) shows that if $\mathrm{P}_{\mathrm{i}}$ and $\mathrm{P}_{\mathrm{j}}$ decrease, on average, by a similar proportion (i.e. a balanced deflation), the original utility level as shown in equation (1) can be achieved with a lower income level. Hence, under a balanced deflation emanating from a financial crisis, the relevant variables measuring consumer utility are consumptions and income level (note 2). During a financial crisis, a decrease in current income (due to a pay cut for instance) leads to a fall in consumption. However, a balanced deflation leads to a rise in income, which renders consumption to increase. It is unclear which income effect is higher than the other.

The above shows that changes in consumer utility (CU) due to a financial crisis depend on changes in consumptions and current income. The behavioral life-cycle hypothesis, however, postulates that current consumption is not only affected by change in current incomes but also changes in future perceived incomes (Shefrin \& Thaler, 1988). A financial crisis leads to a fall in future perceived income if a consumer becomes pessimistic about the future, which then leads to a fall in current consumption. Hence, utility in essence depends on consumption and both current and future incomes. That is:

$$
\mathrm{U}=\mathrm{f}(\mathrm{X}, \mathrm{Y})
$$

where $\mathrm{X}=\Sigma \mathrm{X}_{\mathrm{i}}+\Sigma \mathrm{X}_{\mathrm{j}}$ and $\mathrm{Y}$ denotes present value of current and future incomes stream.

The present value of perceived future incomes is a subjective concept. $\mathrm{Y}$ is affected by a financial crisis because a consumer's perception of her future income depends on how future outlook conjures up in her mind. In this paper, we conjecture that future outlook perceived by a worker is influenced by her emotional state evoked by the GFC. If the GFC gives rise to anxiety or even fear about her future, she perceives a lower future income and consume less now. This constitutes a mediated/indirect effect of the GFC. The GFC may also affect utility indirectly via changes in one's saving culture. In this case, changes in saving value or habit seem to affect her consumption, but not income. This is contrary to changes in emotion which affect both incomes and consumption as proposed by the behavioral life cycle model. Therefore, in our empirical model, utility is correctly measured by both consumption and income.

\subsection{Impacts of the GFC}

The GFC, originated from US in 2008, was attributed to several reasons, including: the subprime mortgage failure; downward spiral of the housing prices; creations of CDO, which are complicated securities based on pools of other mortgages; excessive leverage; weaknesses of the currency default swap (CDS) markets; rising delinquencies; and financial regulation failures. In this paper, however, the GFC is modeled as an exogenous shock. When the GFC plunges the US economy and many developed nations into recessions, the growth of the Chinese economy fell to $6.8 \%$ in the fourth quarter of 2008 from 13\% in 2007. Besides sharp decline in GDP growth, the Chinese economy suffered from escalating unemployment, corporate bankruptcy or company closure, massive layoff, retrenchment and pay cuts. Another very important measure or indicator of GFC is export decline, which was deemed to be the most important reason for the slowdown, considering the sheer size and importance of China's export sector (Yu, 2010). Hence, these economic indicators (EI) are used in this paper to represent the GFC. Our EIs are not mathematically constructed, but simply measurable information cues which can exert impacts on consumer utility. 
For example, in our questionnaire, we ask how information about the increases in unemployment affects the consumers.

The GFC was observed to have direct adverse impacts on the GDP. Changes in GDP, however, might not necessary reflect changes in economic welfare of the households. In this paper, we thus investigate the GFC impact on CU, which is a more exact and appropriate measure of consumer welfare. In the literature, some economists conjectured that there has been an adverse effect of the GFC on China simply because of the declines in GDP and employment. There is hitherto a paucity of empirical or statistical tests of significance: was China's consumer welfare (measured by utility) significantly affected by the GFC?

The data shows that despite the fall in GDP growth, China still experienced on average about $8 \%$ annual growth in 2008 and slightly more than that in 2009. Moreover, aided by the relaxations of the monetary policy via lowering of interest rates and reserve requirements as well as the generous 4 trillion Yuan fiscal policy packages (note 3) think that China might not be seriously affected. In this paper, our survey data was collected in August 2009, which was quite some time after a series of monetary and fiscal interventions by the PRC government. Hence, we examine whether consumer welfare was affected even after the government assistances were implemented.

The merit of our model lies in its ability to capture the indirect effects of the GFC via changes in emotions and saving attitude of the consumers. A literature review shows that these types of causal mediating roles (or indirect effects) have not been examined, theoretically and empirically. Yet, the effects of psychology generated by the GFC and changes in consumer attitude toward the GFC are of paramount importance. These are given due considerations in our model.

\subsection{The Role of Emotions}

The GFC affects the emotional state of an individual (note 4). For instance, in addition to evaporations of personal assets and investment losses including in one's retirement incomes, increasing corporate failure causes firms to retrench workers, rendering job losses or job insecurity (threats of job losses). This creates fear, anxiety, nervousness, etc and causes one to be overly pessimistic about her future, which then affect perception of her future accruable income and hence her utility. Consistent with Tversky and Kahneman (1974), Simon (1986), Thaler (1994) and Slovic et al. (2005), we posit that emotional heuristics, as depicted above, are very important in assessing utility under uncertainty because one's objective or analytic processes could be maimed by ignorance of the crisis, inability to control the situation, information asymmetry, or simply the fact that information about a financial crisis is too complicated or difficult to comprehend. Loewenstein (2000) found that emotions play an important role in affecting one's wellbeing. The importance of the role of emotion was confirmed by Kahneman (2003) who distinguished affective heuristics from "deliberative rationality". Bechara and Damasio (2005) posited that rational choices often depend on prior emotion rather than on complex information processing. In other words, emotion heuristics help in one's decision making processes. Chaudhury (2005) showed that emotional responses to information sources (such as increases in bankruptcy rates) were common under uncertainty. Finucane et al. (2000) posited that emotions often facilitate perceptions. In our model, perception of changes in one's future income is likely to be affected by her emotional states. Hence, a model which omits emotion, either as a measure or as a mediator, for evaluating consumer welfare under uncertainty appears to be flawed. This paper tests if this is the case.

\subsection{The Role of Saving Culture or Value}

Personal saving culture or values is another possible causal factor that may influence CU. For instance, some individuals may become more frugal as they perceive that difficult times ahead could be worse than before (note 5). Others may become more spend thrift (less frugal) believing that saving for the future can be elusive and futile because wealth may be easily or ultimately eroded by the onslaughts of unexpected crises. Therefore, it is of interest to investigate whether consumer's attitude to saving for the future or frugal lifestyle so ingrained in the Chinese society was altered by the GFC and if this had significant impact on utility. In our empirical analysis, frugality is measured by a budget spending mentality and an intensive saving/investment habit (note 6). In China, such saving cultures contribute to high domestic saving rates.

\section{A Model of Structural Utility Mediation}

Our structural utility mediation model comprises both the direct effect of the GFC on CU as well as its indirect effects via emotion heuristics and changes in saving attitude. The direct effect of the GFC on CU is represented by pathway c. Our model has three indirect mediating pathways: (1) pathways a and b via emotion; (2) pathways $d$ and e via saving culture; and (3) pathways a, f and e via emotion and saving culture. It is a structurally integrated model because the exogenous variable (GFC), the causal mediators (emotion and saving culture) and the endogenous variable $(\mathrm{CU})$ are linked together, directly and indirectly, within a closed recursive analytical framework. Such a 
structural mediations model is more appropriate to be measured using SEM, which is presented in the next section.

Unlike a regression model which examines how each of the independent variable directly affects a single dependent variable, SEM models can be used to examine how the various independent and dependent variables affect one another and whether their structural relationships or linkages of variables significantly fit together. Besides, SEM models are conveniently developed and measured via graphical modeling interfaces, with different mathematical equations or linkages across variables instantaneously built into the SEM models such as programmed by the software AMOS. Hence, a large number of models can be tested without the need to formulate the different sets of equations over and over again. SEM is therefore very useful for building and testing a wide range of economic models.

Our structural model, depicted in Figure 2, consists of four latent constructs: GFC, emotion, saving culture and utility. A latent construct can be an abstract concept and usually non-measurable. For example, utility is an abstract concept. To measure such a concept, quantifiable terms such as consumption and income, insofar as they are theoretically relevant, must be employed. The inclusion of multiple measurable items has the merit of reducing the error of measuring a particular latent construct. In our structural model, GFC, a non-measurable latent, is measured by such items as unemployment, export decline, corporate bankruptcy and GDP decline (note 7). These measures are poised in our questionnaires to investigate how export decline as an information source for instance affect one's emotion and consumption. Emotion latent is measured by feeling of uneasiness, nervousness, anxiety and fear. Our factor analysis shows that fearfulness and nervousness are the important items to be included in our structural model. The saving culture latent is measured by a couple of frugality indicators and finally the CU latent is measured by two items, namely, consumption and income (note 8). The income indicator is poised in the questionnaire such that it can be used to capture both current and future incomes.

In our SEM analysis, the four latent constructs outlined above and their relevant measurable items are causally linked together within a structural framework as depicted in Figure 2. Ovals are used to depict the latent constructs, rectangles shows the measureable item/indicator, and circles represents the measurement errors (refer to Bollen, 1989; Hayduk, 1996). The causal pathways are represented by the arrows pointing from one box to another. Note that financial crisis is a single-item latent as the use of multiple items, judging from our confirmatory factor analysis, did not improve the accuracy of its measure.

\section{Data and Empirical Results}

In this paper, the household survey data randomly collected by China's Statistical Bureau were used for our empirical analysis. The cross-sectional data from 19 Chinese provinces were collected in August 2009. 10,043 households responded to our standard questionnaires. The empirical results (path coefficients) are presented in Table 1 .

The null hypothesis implicit in SEM is that the empirical model does not significantly fit the data well $(p<0.05)$. In our analysis, we obtain a non-significant $p$ value of $0.345(\mathrm{df}=9$; Chi-square $=10.063)$, implying that our overall structural model fits the data very well. This verifies the importance of both the emotion heuristics and saving culture in facilitating the assessments of consumer utility.

It is of interest that the indirect effect via emotion (pathways a and b) was reported to have exerted stronger effect on consumer utility than the direct effect (pathway c), as shown by their significant and larger path coefficients. The analysis confirms the importance of anticipatory feelings in influencing consumer utility. An implication is that if the indirect effect or the mediating heuristic role of emotion is neglected or omitted, the change in consumer welfare would be erroneous or misleading. Our results also verify the unilateral theoretical model of Caplin and Leahy (2001).

Saving culture or attitude also constitutes an important mediator for our overall structural model. However, the path coefficients $d$ and e were observed to be small in magnitude, implying that the role of saving culture is not as important as that of emotion. We also found that the saving culture was significantly affected by emotion emanating from the GFC, and these two causally related mediators jointly affect CU. This demonstrates the crucial importance of emotion heuristics in our structural utility mediations model.

\section{Conclusions and Policy Implications}

Consumer welfare as represented by consumer utility in China was found in this paper to be significantly affected by the GFC. Changes in negative information such as declines in exports associated with the GFC affected consumer utility directly as well as indirectly via the mediating roles of emotion and saving culture. The traditional value of frugality, so ingrained in the Chinese culture, was also affected by the GFC, but its mediating effect appeared to be overwhelmed by the sheer importance of the psychological states of the consumers. This paper shows that the 
traditional utility or rational choice theory without anticipatory feelings cannot adequately explain the effects of an economic crisis on consumer utility. Resorting to such models, as was the case with many previous studies, could result in erroneous assessment of consumer utility, pointing to the deficiency of the conventional utility models.

Unlike the US and many other European countries, social welfare and government support are relatively low in China. Hence it seems to be appropriate for China to introduce more social safety nets such as pension schemes, temporary government assistances, and other relevant public policy measures especially in times of a financial crisis. Such initiatives, which could protect their current as well as perceived future incomes, help to allay the declines in income and consumption. These are made possible, as predicted by our structural model, by their ability to allay or reduce the households' anxiety evoked by the GFC. This way, social welfare, which is an additive function of the individual consumer utility, can be enhanced. The government's objective of social stability can also be streamlined.

\section{References}

Bechara, A., \& Damasio, A. (2005). The somatic marker hypothesis: a neural theory of economic decision. Games Econ. Behav., 52, 336-372. http://dx.doi.org/10.1016/j.geb.2004.06.010

Bollen, K.A. (1989). Structural equations with latent variables. New York: Wiley.

Bollen, K.A., \& Davis, W.R. (2010). Causal indicator models: Identification, estimation and testing. Structural Equation Modeling, 16, 498-522. http://dx.doi.org/10.1080/10705510903008253

Byrne, B.M. (2010). Structural equation modeling with AMOS: Basic concepts, applications, and programming $\left(2^{\text {nd }}\right.$ ed.). New York: Taylor and Francis.

Caplin, A., \& Leahy, J. (2001). Psychological expected utility theory and anticipatory feelings. Quarterly Journal of Economics, 116(1), 55-79. http://dx.doi.org/10.1162/003355301556347

Chaudhury, A. (2006). Emotion and reason in consumer behavior. Butterworth: Heinemann.

Finucane, M.L., Alhakami, A., Slovic, P., \& Johnson, S.M. (2000). The affect heuristic in judgements of risks and benefits. Journal of Behavioral Decision Making, 13(1), 1-17.

Hayduk, L.A. (1996). Lisrel, issues, debates and strategies, Baltimore: Johns Hopkins University Press.

Kahneman, D. (2003). Maps of bounded rationality: Psychology for behavioral economics. American Economic Review, 93(5), 1449-75. http://dx.doi.org/10.1257/000282803322655392

Kline, R.B. (2010). Principles and practice of structural equation modeling ( $3^{\text {rd }}$ ed.). New York: Guilford Press.

Iacobucci, D., Saldanha, N., \& Deng. X. (2007). A meditation on mediation: Evidence that structural equations models perform better than regressions. Journal of Consumer Psychology, 17(2), 140-154. http://dx.doi.org/10.1016/S1057-7408(07)70020-7

Loewenstein, G. (2000). Emotions in economic theory and economic behavior. American Economic Review, 90(2), 426-432. http://dx.doi.org/10.1257/aer.90.2.426

Shefrin, H.H., \& Thaler. R.H. (1988). The behavioral life-cycle hypothesis. Economic Inquiry, 26, 609-643. http://dx.doi.org/10.1111/j.1465-7295.1988.tb01520.x

Simon, H.A. (1986). Rationality in psychology and economics. Journal of Business, 59(4), 209-224. http://dx.doi.org/10.1086/296363

Slovic, P., Peters, E., Melissa, L.F., Donald G., \& MacGregor, D.G. (2005). Affect, risk and decision making. Health Psychology, 24(4), 35-40. http://dx.doi.org/10.1037/0278-6133.24.4.S35

Thaler, R.H. (1994). Psychology and savings policies. American Economic Review, 84(2), 186-192.

Tversky, A., \& Kahneman, D. (1974). Judgment under uncertainty: Heuristics and biases. Science, 185(4157), 1124-1131. http://dx.doi.org/10.1126/science.185.4157.1124

Tversky A., \& Kahneman, D. (1981). The framing of decisions and the psychology of choice. Science, 211, 453-458. http://dx.doi.org/10.1126/science.7455683

Varian, H.R. (2010). Intermediate microeconomics: A modern approach $\left(8^{\text {th }}\right.$ ed.). New York: Norton.

Yang, Y., \& Green, S.B. (2010). A note on structural equation modelling estimates of reliability. Structural Equation Modeling, 17(1), 66-81. http://dx.doi.org/10.1080/10705510903438963

$\mathrm{Yu}, \mathrm{Y}$. (2010). The Impact of the global financial crisis on the Chinese economy and China's policy responses. Retrieved November 21, 2010, from www.twnside.org.sg 


\section{Notes}

Note 1. SEM is superior to a regression model for several reasons: it can be used to capture multiple dependent variables and therefore indirect or mediating relationships; it reflects real-life situations in which various variables are intricately linked together, as they are closely related to one another. Using SEM for developing and testing new models constitutes a novelty of this paper.

Note 2.Hence, in our empirical analysis, $\mathrm{CU}$ is measured by income and consumptions only, as a balanced deflation translates general price reduction into an income effect.

Note 3. The export sector was also helped by way of a stoppage in the RMB revaluations since the onslaught of the GFC. Prior to the GFC, from 2005 to early 2008, the RMB was revalued on average by about $19 \%$. The revaluation was temporarily halted during the GFC. Since June 2010, some revaluations were allowed by instituting the policy of a managed float.

Note 4. This paper examines four emotional states commonly used for depicting workers' responses to a financial crisis: feelings of unease, anxiety, fear and nervousness. Consumers, especially those whose jobs are unstable, as in China's massive informal economy where permanent job contracts are lacking, might be more nervous or anxious, if not fearful, about the future.

Note 5. In this case, frugality is a saving attitude or habit which cannot be easily changed unless a big exogenous shock such as the GFC erupted.

Note 6. Savings in banks are the most important conduits of their excess funds following the increasing risks of other investment channels during the GFC. Most people saved in the local banks given that the safety of the deposits in banks was guaranteed by the government.

Note 7. Our empirical analysis shows that not all the GFC indicators affect, directly or indirectly, to the same extent. For example, our factor analysis shows that export decline had more substantial impacts on the consumers probably because many workers were engaged in export industries for which China is a powerhouse, and a change in export might have altered their incomes directly, which adversely affected their psychological states. We also found that decline in GDP has a smaller impact on Chinese consumers, probably because economic growth in China, despite the GFC, remained at a relatively high level.

Note 8. In regression analysis, multicollinearity can be a serious problem if income and consumption are used concurrently as independent variables for quantifying consumer utility. However, such a concern is allayed in SEM even though two or more items used for measuring the latent may be somewhat co-related (see also Iacobucci et al. 2007).

Table 1. Path coefficients

\begin{tabular}{|c|c|c|c|c|c|}
\hline $\mathrm{a}$ & $\mathrm{b}$ & $\mathrm{C}$ & $\mathrm{d}$ & $\mathrm{e}$ & $\mathrm{f}$ \\
\hline $0.134^{* * *}$ & $-0.202^{* * *}$ & $-0.114^{* * *}$ & $0.040^{*}$ & $0.065^{* *}$ & $0.111^{* * *}$ \\
\hline
\end{tabular}

Note: $\mathrm{p}<0.10^{*}, \mathrm{p}<0.05^{* *}, \mathrm{P}<0.01 * * *$

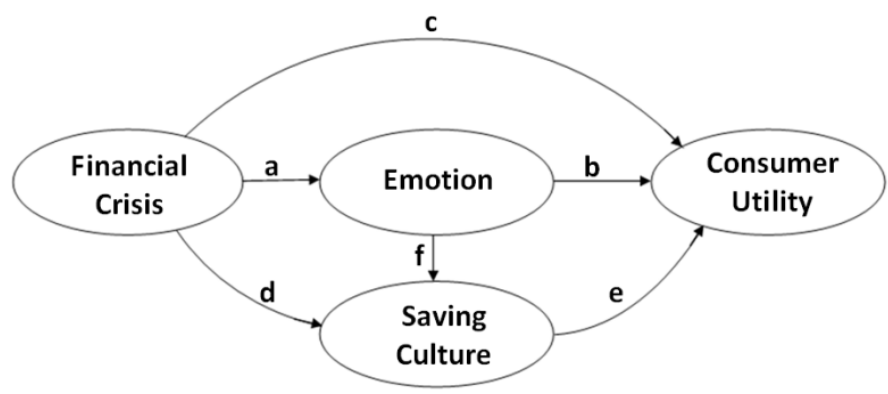

Figure 1. Path Diagram: Structural Utility Mediation Model 


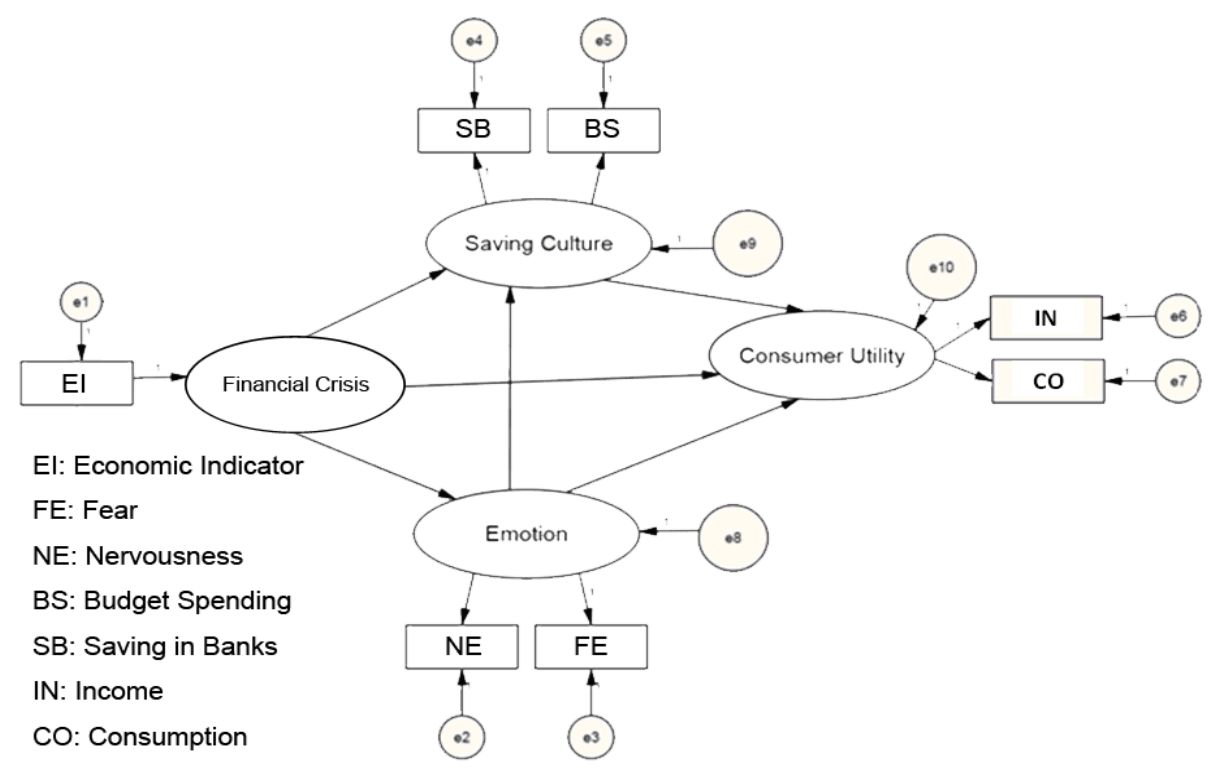

Figure 2. SEM: Structural Utility Mediation Model 